\title{
NOMINA NUDA ARE NOT ILLEGITIMATE!
}

by

\author{
H. C. D. de Wit (Wageningen)
}

Art. 22 of the Code rules that nomina nuda have "no status" and "no claim to recognition by botanists". The term "nomina nuda" is not used - the Code contains no definition of nomina nuda - but, clearly, nomina nuda are not validly published (Art. 42, first paragraph, sub (2)).

Nevertheless, though not recognized, nomina nuda make their presence, time and again, painfully felt. Often I have participated in discussions that ensued from the presence of nomina nuda, particularly in suspected homonymy of specific names.

These discussions were brought about by a careful consideration of the Code and not infrequently it was decided to adopt a solution which seemed logical even if some uncertainty remained whether we had really adhered to the Code or not. I wish to survey some points illustrating the line of reasoning sometimes followed. It will be proposed that some small amendments to the Code might lead to greater clarity and the avoidance of mistakes. I claim that adoption of these proposals would also contribute to stabilization of specific names.

Rec. 54 D. "Authors should avoid adoption of a name or an epithet which has been previously published as a nomen nudum."

This implies that a nomen nudum does not render illegitimate a later homonym. If it did, this Recommendation would be superfluous and irrelevant. On this ground botanists decide that a specific name homonymous with an earlier nomen nudum, though undesirable, if they wish so, may stand.

Art. 73, second paragraph. "The publication of an epithet in an illegitimate combination must not be taken into consideration for purposes of priority (see Art. 53) except in the rejection of a later homonym (Art. 74).

It may be gathered from the final phrase of this paragraph that an illegitimate 
combination leads to the rejection of a later homonym. An illegitimate name (or combination) is one that is contrary to the rules (Art. 10). A nomen nudum is contrary to Arts 42 and 52. And so it is believed that a nomen nudum is an illegitimate name and, according to Art. 73, it might cause the rejection of a later homonym. A specific name is rejected on account of the existence of an earlier nomen nudum.

The reality of this view is demonstrated by the case of Pseudotsuga taxifolia (Poir.) Britton. This name was replaced by P. menziesii (Mirb.) Franco, which led to fervent reactions, even to an official resolution of the Society of American Foresters. However, Boivin demonstrated recently (Bolet. Socied. Broter. 28: 63-64, 1954) that this name change rests on a supposed illegitimacy of the name Pseudotsuga taxifolia. There exist earlier names but these are, in reality, nomina nuda. There appears to be no need at all to change the name Pseudotsuga taxifolia.

The error in procedure is caused by a misunderstanding of the term "illegitimate". Art. 73, when referring to "illegitimate combinations" does not include nomina nuda. According to Art. 22 "A name of a taxon has no status under this Code, and no claim to recognition by botanists unless it is validly published", nomina nuda are without status and are not recognized: they are not illegitimate, have no claim to the status of illegitimacy: they are entirely to be ignored. A later homonym of a nomen nudum, therefore, is allowed, though better avoided (Rec. 54, D).

Art. 53, second paragraph: "For purposes of priority, however, only legitimate names and epithets published in legitimate combinations are taken into consideration (see Arts 10, 73 and the exception to this rule mentioned in Art. 74). Now in Art. 74 it is stated: (2nd sentence) "Even if the earlier homonym is illegitimate .... the later homonym must be rejected."

In the same way as before, botanists when believing that a nomen specificum nudum is illegitimate, are inclined to reject later homonyms, which results in name changes. It has been demonstrated that the application of Art. 22 prevents rejection for such reasons.

As regards Art. 81, 3rd sentence, it should be stressed that a nomen nudum can never be regarded as an illegitimate combination.

Art. 81, third sentence. "When a new epithet is required, an author may, if he wishes, adopt an epithet previously given to the taxon in an illegitimate combination, if there is no obstacle to its employment in the new position or sense; the epithet in the resultant combination is treated as new."

The first half of this sentence is phrased in a manner strongly reminiscent of Rec. 54 D. It opens a possibility of using an epithet derived from an illegitimate combination, if the author wishes. Rec. 54 D also opens the possibility of using the epithet derived from a nomen nudum, if the author wishes. This analogy probably added to lead botanists up the garden path.

Summarizing the position I find that Rec. 54 D, Art. 22, and Art. 81, if remembered together, may suggest that a specific name can stand or be coined in spite of earlier nomina nuda. On the other hand Arts. 53, 73, and 74 suggest to botanists who fail to realize that Art. 22 actually rules out all nomina nuda once and forever, that homonymous or synonymous specific names must fall if earlier nomina nuda exist. Although a strict application of the Code solves these difficulties, in practice it appears that the Code is not "sufficiently clear", as it should be (Art. 4).

This state of affairs seems unsatisfactory to me. It causes and has caused, confusion. There is a simple means to put a first step towards more clarity. Art. 22 contains a reference to Art. 42. If Art. 42 contained a back reference to Art. 22 this would stress the nomenclatural non-existence of nomina nuda. There is, however, another problem connected with the insertion of this most desirable reference or indication. 
Nowhere in the Code any definition is given of a nomen specificum nudum, though there are thousands of them to be found in effectively published botanical literature. What is a nomen nudum? A binomial without any accompanying text evidently is a nomen nudum. Every taxonomist is also well acquainted with binomials adorned by texts like: "a tree in the mountains", "used for house-building", "abundant in the forests", or by one or more vernacular names as equivalents. These are the so-called "nomina semi-nuda", which are essentially just as naked and useless for taxonomical and nomenclatural purposes as any undiluted nomen nudum.

Nomina nuda and nomina semi-nuda, I hold, could be regarded as of one kind, according to their nature. They are all "nomina nuda".

It is very difficult to draft a delimitation of what are nomina nuda (in the wider sense) and what are binomials valid under the Code.

One might suggest that a valid binomial should be at least accompanied by words of diagnostical value, characterizing or describing the taxon in some way intended to make it recognizable to others. Evidently, this is what we want and should decide whether a binomial is a nomen nudum or not.

A binomial, for example Lamium album, without any accompanying description is already diagnostical. Should this binomial have been published without any accompanying text, it would be considered to be a nomen nudum and accordingly be rejected and not recognized. If the same taxon were later introduced into effectively published literature as "Lamium ruderale, a plant with opposite leaves and a white, sympetalous two-lipped corolla" it would certainly stand a good chance of being accepted under the name Lamium ruderale, although the diagnostical value of both publications is exactly the same.

I think it best not to try for a delimitation of nomina nuda in a wider sense. If a name is published without any accompanying text, although it may be of diagnostical value by itself, there is no problem (Art. 22). If it is published with an accompanying text without any diagnostical value, it should be treated similarly and not be regarded as validly published. It is a nomen nudum as well. In cases where there is doubt if the text to the name is of diagnostical value, a policy might be adopted comparable to that of the type method (designation of types).

Art. 22 is basal for this problem. Nomina specifica nuda (and specifica semi-nuda) should have no status and receive no recognition in nomenclature. They do not and should not cause the rejection of later specific names, which are otherwise valid. Recommendation 54, D, of course, should stand.

I think that botanists have a right that their legislature give unambiguous guidance in this matter and propose therefore the following alterations to the Code.

To be added to Art. $42 *$ ):

Note. A nomen specificum nudum is a binomial occurring in effectively published literature without any accompanying text or accompanied by words considered to be without diagnostical value. Nomina specifica nuda are not recognized by the Code (see Art. 22).

New Recommendation (to follow Art. 42) **):

Once a binomial is designated by name as a nomen specificum nudum in effectively published literature the decision ought to be followed unless an error in judgment can be proved. -

I believe that these proposals, if adopted, will add to a better understanding of the Code as regards nomina specifica nuda (and nomina specifica semi-nuda), also, and this is perhaps more important, that monographers and revisers of taxa are

*) Proposal no 2 submitted to the 9th International Botanical Congress, Montreal 1959.

**) Proposal no 3 idem. 
provided with a new weapon by which nomina specifica semi-nuda, threatening to uproot established usage of a specific name, can often be reduced to harmlessness. Adoption will add to the stabilization of specific names.

Finally, I wish to thank Dr. Stafleu for his kind help and advice for the composition of this paper. 